\title{
Laparoendoscopic Single-Site and Conventional Laparoscopic Adrenalectomy: A Matched Case-Control Study
}

\author{
Byong Chang Jeong, M.D., Ph.D.,' Yong Hyun Park, M.D., \\ Deok Hyun Han, M.D., Ph.D., and Hyeon Hoe Kim, M.D., Ph.D.
}

\begin{abstract}
Purpose: The purpose of this study was to describe our initial clinical experience and assess the feasibility of laparoendoscopic single-site surgery (LESS) in the treatment of benign adrenal adenoma.

Patients and Methods: Nine patients undergoing LESS adrenalectomy for benign adrenal adenoma were compared with 17 patients undergoing conventional laparoscopic adrenalectomy. Controls were matched for age, sex, surgical indications, and tumor size via a statistically generated selection of all conventional laparoscopic adrenalectomies performed during the same period of time.

Results: No significant differences in the mean operative time (169 vs. 144.5 minutes, $p=0.287)$, blood loss (177.8 vs. $204.7 \mathrm{~mL}, p=0.792$ ), and postoperative hospital stay ( $3.2 \mathrm{vs} .3 .5$ days, $p=0.525$ ) were observed between the LESS and conventional laparoscopy group. However, postoperative pain, as measured by the number of days of intravenous (IV) patient controlled anesthesia use, was significantly lower in the LESS group (0.9 vs. 1.9 days, $p=0.047)$. Perioperative complications were similar between the two groups.

Conclusions: LESS adrenalectomy for benign adrenal adenoma is comparable to the conventional laparoscopic approach with regard to the operative time, blood loss, length of hospital stay, and degree of complication, and has demonstrated more desirable cosmetic outcomes.
\end{abstract}

\section{Introduction}

T

HE FIRST LAPAROSCOPIC adrenalectomy was performed in 1992. ${ }^{1}$ The use of laparoscopy to remove benign adrenal tumors has since increased at a rapid place. Because of its less invasive nature, the procedure is now considered superior to open adrenalectomy. ${ }^{2,3}$ Recently, an even less invasive alternative to the conventional laparoscopic surgery has been developed, laparoendoscopic single-site surgery (LESS). LESS is an attempt to further enhance the cosmetic benefits of minimally invasive surgery while minimizing the potential morbidity associated with multiple incisions.

Preliminary advances in LESS, as applied to urologic diseases, demonstrate that the techniques are feasible with advanced skills and optimal instrumentation. ${ }^{4}$ However, to our knowledge, there are no published reports on the application of LESS for the treatment of benign adrenal adenoma. Herein, we describe our initial clinical experience and evaluate the feasibility of LESS in the treatment of benign adrenal adenoma.

\section{Patients and Methods}

\section{Patients}

We performed 79 conventional laparoscopic adrenalectomies from June 2001 to January 2009 and 9 LESS adrenalectomies from March 2009 to May 2009. To obtain uniform background factors, we conducted a matched case-control study to compare the surgical outcomes from patients who underwent either LESS adrenalectomy $(n=9)$ or conventional laparoscopic adrenalectomy $(n=17)$. Patients were matched with the 1:2 ratio with regard to age, sex, surgical indications, and tumor size. The study was approved by the Institutional Review Board at the Seoul National University Hospital.

\section{Operative technique}

Surgery was performed by two experienced laparoscopic surgeons (H.H. Kim and B.C. Jeong). Both procedures were performed with the patient in the flank position with the affected side elevated to $70^{\circ}$. Regarding the conventional

\footnotetext{
${ }^{1}$ Department of Urology, Sungkyunkwan University College of Medicine, Seoul, Korea.

${ }^{2}$ Department of Urology, Seoul National University College of Medicine, Seoul, Korea.
} 


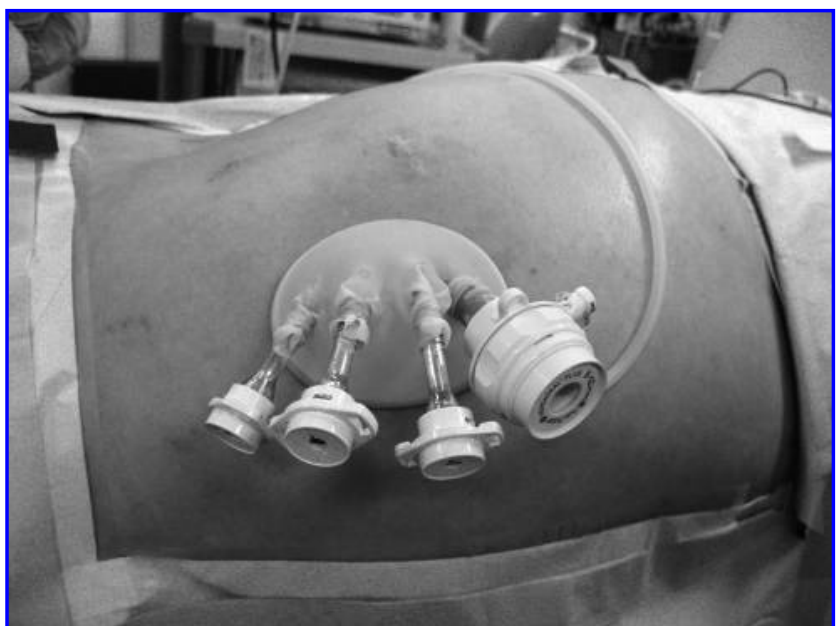

FIG. 1. Home-made single-port device used in laparoendoscopic single-site surgery adrenalectomy.

laparoscopic approach, usually three or four trocars were used. A 10-mm trocar was inserted along the midclavicular line at the umbilicus level for the laparoscope. Additional two $5-\mathrm{mm}$ trocars were inserted along the anterior axillary line, one below the costal margin and the other at the umbilicus level. The fourth 5-mm trocar for liver retraction was inserted just below the xyphoid process. After incision on the peritoneal reflection along the liver edge for right adrenal lesion or incision on the white line of Toldt for left adrenal lesion, the adrenal gland was identified. Once the adrenal vein was secured, the adrenal gland was mobilized from the upper pole of kidney with hook cautery, coagulating scissors, or ultrasonic scissors. After adrenalectomy, the laparoscopic bag was placed through the camera port and then the specimen was extracted in total.

Regarding the LESS approach, the home-made single-port device was inserted at the umbilicus through a $2-\mathrm{cm}$ incision (Fig. 1). ${ }^{5}$ The Alexis wound retractor was inserted at the umbilicus through a $20-\mathrm{mm}$ incision. A home-made singleport device was constructed by securing the fingers of a size $61 / 2$ surgical glove to the end of three or four trocars with a rubber band and fixed to the outer ring of the wound retractor. After insufflation of the abdomen with $\mathrm{CO}_{2}$ gas, a 5-mm flexible laparoscope with an integrated camera head (EndoEye; Olympus, Orangeburg, NY) was introduced. Adrenalectomy was performed with the roticulating laparoscopic instrument (dissector, grasper, and scissors) from Covidien (Norwalk, CT) to create the required angle, and hook cautery and ultrasonic scissors that were part of the standard laparoscopic instrumentation set, using procedures similar to those of the conventional laparoscopic adrenalectomy without additional extraumbilical incisions. The specimen was placed inside the laparoscopic bag and retrieved through the abdominal incision.

\section{Outcome measurement and statistical methods}

Various parameters were analyzed, including operative time, estimated blood loss, resumption of oral intake, complications, and length of hospital stay, to draw a comparison between LESS and conventional laparoscopic adrenalectomy.
Table 1. Baseline Characteristics of Patients According to Surgical Procedure

\begin{tabular}{|c|c|c|c|}
\hline & $\begin{array}{c}\text { LESS } \\
\text { adrenalectomy }\end{array}$ & $\begin{array}{l}\text { Conventional } \\
\text { laparoscopic } \\
\text { adrenalectomy }\end{array}$ & $\mathrm{p}$-Value \\
\hline No. of patients & 9 & 17 & - \\
\hline $\operatorname{Sex}(\%)$ & & & 0.281 \\
\hline Male & $4(44.4)$ & $11(64.7)$ & \\
\hline Female & $5(55.6)$ & $6(35.3)$ & \\
\hline Age (years) & $46.0(26-64)$ & $43.8(19-72)$ & 0.458 \\
\hline ASA score (\%) & & & 0.258 \\
\hline 1 & $3(33.3)$ & $4(23.5)$ & \\
\hline 2 & $3(33.3)$ & $11(64.7)$ & \\
\hline 3 & $3(33.3)$ & $2(11.8)$ & \\
\hline $\begin{array}{l}\text { Preoperative } \\
\quad \text { diagnosis (\%) }\end{array}$ & & & 0.992 \\
\hline $\begin{array}{l}\text { Nonfunctioning } \\
\text { adenoma }\end{array}$ & $3(33.3)$ & $6(35.3)$ & \\
\hline Cushing's syndrome & $1(11.1)$ & $2(11.8)$ & \\
\hline Pheochromocytoma & $5(55.6)$ & $9(52.9)$ & \\
\hline Laterality $(\%)$ & & & 1.000 \\
\hline Right & $3(33.3)$ & 7 (41.2) & \\
\hline Left & $6(66.7)$ & $10(58.8)$ & \\
\hline
\end{tabular}

LESS = laparoendoscopic single-site surgery; ASA = American Society of Anesthesiologists.

Differences in demographics, clinical, and surgical results were examined using the Mann-Whitney $U$-test and chisquare test for continuous and categorical variables, respectively. All $p$-values were two-sided, and $p<0.05$ was considered significant.

\section{Results}

No significant differences were observed in age, sex, side of adrenalectomy, and diagnosis between groups 1 and 2 (Table 1).

There was one conversion to conventional laparoscopic surgery in the LESS group and one conversion to open surgery in the conventional laparoscopy group. Cause of conversion in the LESS group was bleeding from the splenic laceration. Inspection of the most lateral aspect of the splenic body revealed a vertical laceration approximately $5 \mathrm{~cm}$ long, reaching deep into the pulp of the spleen, and bleeding significantly. Attempts to control bleeding using flexible instruments were unsuccessful. Therefore, the decision was made to proceed with a conventional laparoscopy and suturing of the splenic body. After suturing, the splenic bed was then reinspected, revealing good hemostasis and showing no other source of bleeding.

No significant differences were observed in mean operative time (169.2 vs. 144.5 minutes, $p=0.287$ ), blood loss (177.8 vs. $204.7 \mathrm{~mL}, p=0.792$ ), and postoperative hospital stay (3.2 vs. 3.5 days, $p=0.525)$ between the LESS and conventional laparoscopy group (Table 2). Postoperative pain, as measured by the number of days of IV patient controlled anesthesia use, was significantly lower in the LESS group, with a mean of 0.9 days (range 0-2 days), compared with 1.9 days (range 1-4 days) in the open group ( $p=0.047)$. Perioperative complications were similar between the two groups. Complications included serosa tearing of small bowel which was 
Table 2. Surgical Outcomes According to Surgical Procedure

\begin{tabular}{lccc}
\hline & $\begin{array}{c}\text { LESS } \\
\text { adrenalectomy }\end{array}$ & $\begin{array}{c}\text { Conventional } \\
\text { laparoscopic } \\
\text { adrenalectomy }\end{array}$ & p-Value \\
\hline $\begin{array}{l}\text { Conversion (\%) } \\
\text { Mass size (cm) }\end{array}$ & $1(11.1)$ & $1(5.9)$ & 1.000 \\
$\begin{array}{l}\text { Operative time } \\
\quad \text { (minutes) }\end{array}$ & $169.2(1-5.4)$ & $4.3(2.5-6.0)$ & 0.011 \\
$\begin{array}{l}\text { Estimated blood } \\
\quad \text { loss (mL) }\end{array}$ & $177.8(50-400)$ & $204.7(10-900)$ & 0.792 \\
$\begin{array}{l}\text { Transfusion (\%) } \\
\text { PCA duration }\end{array}$ & $0.9(0)$ & $144.5(70-300)$ & 0.287 \\
$\quad$ (days) & $1.1(1-2)$ & $1.2(1-3)$ & $1.9(0-4)$ \\
$\begin{array}{l}\text { Resumption of } \\
\quad \text { oral intake (days) }\end{array}$ & $3.2(2-4)$ & $3.5(2-4)$ & 0.047 \\
$\begin{array}{l}\text { Hospital stay (days) } \\
\text { Complication (\%) }\end{array}$ & $1(11.1)$ & $1(5.9)$ & 1.000 \\
\hline
\end{tabular}

$\mathrm{PCA}=$ patient controlled anesthesia.

managed conservatively for the LESS group, and postoperative bleeding required the transfusion of 4 units of blood for the conventional laparoscopy group. No patient in either group experienced a complication related to the blood pressure extremes. The scars receded into the umbilicus and were hardly visible (Fig. 2).

\section{Discussion}

Laparoscopic adrenalectomy has emerged in the last decade as the standard procedure for the majority of patients with benign adrenal adenoma. ${ }^{3,6} \mathrm{New}$ techniques have been developed to decrease the number of ports needed for safe laparoscopic surgery. As a result, interest in the introduction of LESS in various urologic surgeries has increased. ${ }^{4,7}$

The feasibility of LESS in the treatment of various urologic diseases has been verified. Still most surgeons describe LESS as time consuming and challenging, even those with a high level of experience with conventional laparoscopy. Other than improved cosmetic outcomes, the benefit of LESS over the conventional laparoscopic surgery has not yet been determined. Few comparative studies have been conducted to compare LESS with the conventional laparoscopy. A study to assess whether or not outcomes for LESS are approximate to those obtained with a conventional laparoscopic approach would be of particular interest. For this reason, a comparative study of LESS and conventional laparoscopic surgery is needed.

To our knowledge, only one case-control study has compared LESS with the conventional laparoscopic surgery. Raman et $\mathrm{al}^{8}$ compared 11 LESS nephrectomies with 22 conventional laparoscopic nephrectomies. No differences in operative time, postoperative hospital stay, narcotic analgesic use, complication rate, or transfusion requirement were observed between LESS and conventional laparoscopic nephrectomies. However, estimated blood loss was significantly lower in the LESS group than in the conventional laparoscopy group. Therefore, although the limitation of their study is inherent in its retrospective nature, LESS is certainly comparable or preferable to the conventional laparoscopic surgery with regard to the subjective cosmetic results and objective surgical results.

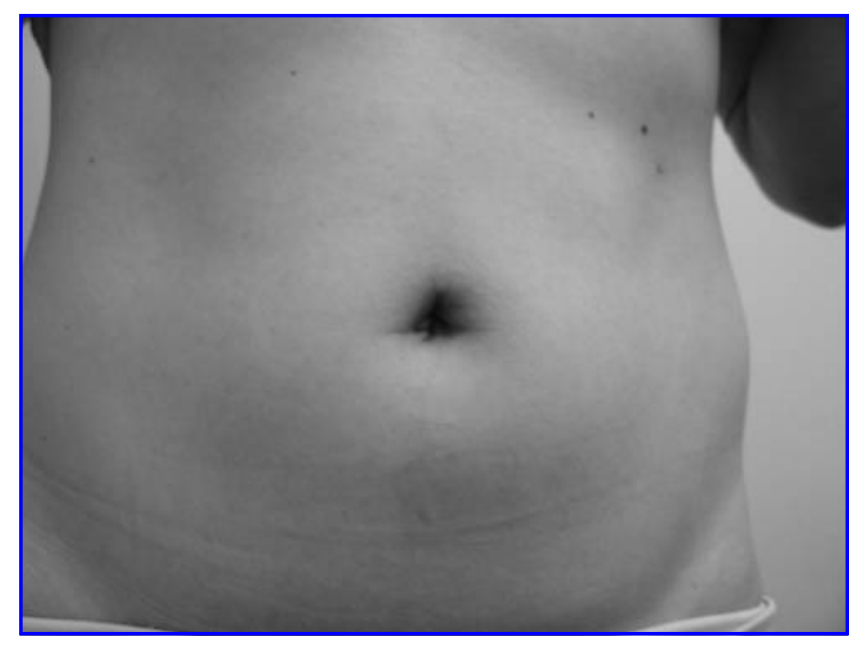

FIG. 2. Postoperative view of the wound.

Although a few studies have demonstrated the feasibility of the LESS adrenalectomy, ${ }^{4}$ evidence-based clinical trial data on this technique has not been provided because of the descriptive nature of the study. To the best of our knowledge, no comparative studies of LESS and conventional laparoscopic adrenalectomy can be found in the literature. Our study is the first known report of a novel minimally invasive surgical approach for the treatment of benign adrenal adenoma with favorable preliminary clinical outcomes comparable with those of the conventional laparoscopic adrenalectomy.

In this study, there were statistically significant size difference between the LESS and conventional laparoscopy group. However, there were several reports that surgery for large adrenal tumors can safely be performed laparoscopically with outcomes comparable to those of surgery for small tumors. ${ }^{9,10}$ And our study showed similar results. There were no significant differences between the mean operative time, postoperative complications, or postoperative stay for patients undergoing LESS or conventional laparoscopic adrenalectomy although their was size discrepancy.

Half of the patients in our study were found to have pheochromocytoma. Although laparoscopic approach has now been adopted for most pheochromocytomas, debate over the use of laparoscopic surgery for pheochromocytoma continues out of concern for hemodynamic instability because of catecholamine release and other complications resulting from hemodynamic instability. It can be speculated that difficulties in dissection during LESS adrenalectomy lead to excessive catecholamine secretion and increased risk of hypertensive crisis. However, our experience demonstrated that an experienced anesthesiology team, appropriate preoperative medical management, and efforts to minimize adrenal manipulation during surgery afforded us the ability to avoid hypertensive crisis in this series.

Limitations of the present study should be addressed as a means for improvement or for mapping of strategies for further study. Such limitations include the fact that there were only a small number of reported cases, as well as the retrospective nature of the study and susceptibility to all biases inherent in such a design. Moreover, the duration of followup is brief to assess the normalization of excessive catecholamine secretion or high blood pressure. However, experience 
with LESS adrenalectomy is still at an infantile stage; the present study could serve as a basis for further studies that include more patients and a longer period of follow-up.

\section{Conclusions}

We described the first series of LESS adrenalectomies for benign adrenal adenoma. We demonstrated the technical feasibility of LESS versus the conventional laparoscopic approach to the removal of benign adrenal adenoma. We found that LESS adrenalectomy is a safe technique resulting in improved cosmetic outcomes, with the additional benefit of being minimally invasive; however, long-term follow-up is necessary. In our opinion, LESS adrenalectomy for benign adrenal adenoma has tremendous potential as a new variant of laparoscopic procedures resulting in fewer scars.

\section{Disclosure Statement}

No competing financial interests exist.

\section{References}

1. Gagner M, Lacroix A, Bolte E. Laparoscopic adrenalectomy in Cushing's syndrome and pheochromocytoma. N Engl J Med 1992;327:1033.

2. Hansen P, Bax T, Swanstrom L. Laparoscopic adrenalectomy: History, indications, and current techniques for a minimally invasive approach to adrenal pathology. Endoscopy 1997;29:309-314.

3. Smith CD, Weber CJ, Amerson JR. Laparoscopic adrenalectomy: New gold standard. World J Surg 1999;23:389-396.

4. Irwin BH, Rao PP, Stein RJ, et al. Laparoendoscopic single site surgery in urology. Urol Clin North Am 2009;36:223235.
5. Park YH, Kang MY, Jeong MS, et al. Laparoendoscopic single-site nephrectomy using a homemade single-port device for single-system ectopic ureter in a child: Initial case report. J Endourol 2009;23:833-835.

6. Melman L, Matthews BD. Current trends in laparoscopic solid organ surgery: Spleen, adrenal, pancreas, and liver. Surg Clin North Am 2008;88:1033-1046.

7. Tracy CR, Raman JD, Cadeddu JA, et al. Laparoendoscopic single-site surgery in urology: Where have we been and where are we heading? Nat Clin Pract Urol 2008;5:561-568.

8. Raman JD, Bagrodia A, Cadeddu JA. Single-incision, umbilical laparoscopic versus conventional laparoscopic nephrectomy: A comparison of perioperative outcomes and short-term measures of convalescence. Eur Urol 2009;55:11981204.

9. Tsuru N, Suzuki K, Ushiyama T, et al. Laparoscopic adrenalectomy for large adrenal tumors. J Endourol 2005;19:537540.

10. Parnaby CN, Chong PS, Chisholm L, et al. The role of laparoscopic adrenalectomy for adrenal tumours of $6 \mathrm{~cm}$ or greater. Surg Endosc 2008;22:617-621.

Address correspondence to: Hyeon Hoe Kim, M.D., Ph.D. Department of Urology Seoul National University Hospital 28 Yeongeon-dong, Jongno-gu Seoul 110-744 Korea

E-mail: hhkim@snu.ac.kr

\section{Abbreviations Used}

LESS = laparoendoscopic single-site surgery $\mathrm{PCA}=$ patient controlled anesthesia 


\section{This article has been cited by:}

1. Sara L. Best, Richard Bergs, Daniel J. Scott, Raul Fernandez, Lauren B. Mashaud, Jeffrey A. Cadeddu . 2012. Solo Surgeon Laparo-Endoscopic Single Site Nephrectomy Facilitated by New Generation Magnetically Anchored and Guided Systems Camera. Journal of Endourology 26:3, 214-218. [Abstract] [Full Text HTML] [Full Text PDF] [Full Text PDF with Links]

2. Linhui Wang, Bing Liu, Zhenjie Wu, Qing Yang, Wei Chen, Haibo Sheng, Zunli Xu, Liang Xiao, Cheng Wang, Yinghao Sun. 2012. Comparison of Single-surgeon Series of Transperitoneal Laparoendoscopic Single-site Surgery and Standard Laparoscopic Adrenalectomy. Urology 79:3, 577-584. [CrossRef]

3. John E Humphrey, David Canes. 2012. Transumbilical laparoendoscopic single-site surgery in urology. International Journal of Urology no-no. [CrossRef]

4. Michael A. White, Jihad H. KaoukLaparoendoscopic Single-Site Surgery: Ports, Access, and Instrumentation 1274-1282. [CrossRef]

5. Daniel Yong, Matvey Tsivian, David M. AlbalaLaparoscopic and Robotic Adrenalectomy 1025-1035. [CrossRef]

6. Soroush Rais-Bahrami, Abhay Rane, Lee RichstoneLaparoendoscopic Single-Site Upper Tract Surgery 1283-1291. [CrossRef]

7. Giovannalberto Pini, Jens Rassweiler. 2012. Minilaparoscopy and laparoendoscopic single-site surgery: mini- and single-scar in urology. Minimally Invasive Therapy \& Allied Technologies 1-18. [CrossRef]

8. Sung Hoon Choi, Ho Kyoung Hwang, Chang Moo Kang, Woo Jung Lee. 2012. Transumbilical Single Port Laparoscopic Adrenalectomy: A Technical Report on Right and Left Adrenalectomy Using the Glove Port. Yonsei Medical Journal 53:2, 442. [CrossRef]

9. Akira Miyajima, Seiya Hattori, Takahiro Maeda, Masanori Hasegawa, Toshikazu Takeda, Eiji Kikuchi, Hiroshi Asanuma, Ken Nakagawa, Mototsugu Oya. 2012. Transumbilical approach for laparo-endoscopic single-site adrenalectomy: Initial experience and short-term outcome. International Journal of Urology no-no. [CrossRef]

10. Ahmad Mohmmad Zubaidi. 2012. Single-Port Laparascopic Cholecystectomy: Scarless Cholecystectomy. Minimally Invasive Surgery 2012, 1-5. [CrossRef]

11. Ha Na Kwak, Jun Ho Kim, Ji-Sup Yun, Byung Ho Son, Woong Youn Chung, Yong Lai Park, Chan Heun Park. 2011. Conventional Laparoscopic Adrenalectomy Versus Laparoscopic Adrenalectomy Through Mono Port. Surgical Laparoscopy, Endoscopy \& Percutaneous Techniques 21:6, 439-442. [CrossRef]

12. Victor Chia-Hsiang Lin, Yao-Chou Tsai, Shiu-Dong Chung, Tin Chou Li, Chen-Hsun Ho, Fu-Shan Jaw, Huai-Ching Tai, Hong-Jeng Yu. 2011. A comparative study of multiport versus laparoendoscopic single-site adrenalectomy for benign adrenal tumors. Surgical Endoscopy . [CrossRef]

13. Evangelos Liatsikos, Iason Kyriazis, Panagiotis Kallidonis, Minh Do, Anja Dietel, Jens-Uwe Stolzenburg. 2011. Pure singleport laparoscopic surgery or mix of techniques?. World Journal of Urology . [CrossRef]

14. Linhui Wang, Bing Liu, Zhenjie Wu, Qing Yang, Wei Chen, Zunli Xu, Cheng Wang, Liang Xiao, Fubo Wang, Yinghao Sun . A Matched-Pair Comparison of Laparoendoscopic Single-Site Surgery and Standard Laparoscopic Radical Nephrectomy by a Single Urologist. Journal of Endourology, ahead of print. [Abstract] [Full Text HTML] [Full Text PDF] [Full Text PDF with Links]

15. Matthew R. Schill, J. Esteban Varela, Margaret M. Frisella, L. Michael Brunt. 2011. Comparison of laparoscopic skills performance between single-site access (SSA) devices and an independent-port SSA approach. Surgical Endoscopy . [CrossRef]

16. Jae Won Lee, Francis Raymond P. Arkoncel, Koon Ho Rha, Kyung Hwa Choi , Ho Song Yu , Yunbyung Chae, Woong Kyu Han . 2011. Urologic Robot-Assisted Laparoendoscopic Single-Site Surgery Using a Homemade Single-Port Device: A Single-Center Experience of 68 Cases. Journal of Endourology 25:9, 1481-1485. [Abstract] [Full Text HTML] [Full Text PDF] [Full Text PDF with Links]

17. Linhui Wang, Zhenjie Wu, Bing Liu, Qing Yang, Wei Chen, Haibo Sheng, Zunli Xu, Cheng Wang, Yinghao Sun. 2011. Transumbilical laparoendoscopic single-site surgery of simple nephrectomy of nonfunctioning kidney: a two-year experience. Journal of Medical Colleges of PLA 26:4, 213-221. [CrossRef]

18. Fatih Tunca, Yasemin Giles Senyurek, Tarik Terzioglu, Yal\#n Iscan, Serdar Tezelman. 2011. Single-incision laparoscopic adrenalectomy. Surgical Endoscopy . [CrossRef]

19. Aly M. Abdel-Karim, Ahmed Moussa, Salah Elsalmy. 2011. Laparoendoscopic Single-site Surgery Extravesical Repair of Vesicovaginal Fistula: Early Experience. Urology. [CrossRef] 
20. Xiaofeng Zou, Guoxi Zhang, Rihai Xiao, Yuanhu Yuan, Gengqing Wu, Xiaoning Wang, Dazhi Long, Yuting Wu, Min Liu, Yijun Xue, Xu Zhang. 2011. Transvaginal natural orifice transluminal endoscopic surgery (NOTES)-assisted laparoscopic adrenalectomy: first clinical experience. Surgical Endoscopy . [CrossRef]

21. Koji Yoshimura, Kazutoshi Okubo, Yoshiyuki Matsui , Hiroyuki Nishiyama, Osamu Ogawa . 2011. Laparoendoscopic Single-Site Surgery for Left Adrenalectomy: Standardization of Technique. Journal of Endourology 25:6, 1031-1035. [Abstract] [Full Text HTML] [Full Text PDF] [Full Text PDF with Links]

22. Antonio Alcaraz, Lluis Peri, Laura Izquierdo, Mireia Musquera, Rodrigo Serapiao, Diego Pachón, Alejandro Miranda, Maria J. Ribal. 2011. Transvaginal NOTES and LESS: Are They the Future in Kidney Surgery?. European Urology Supplements 10:3, e58-e63. [CrossRef]

23. Abhay Rane, Luca Cindolo, Luigi Schips, Marco Sio, Riccardo Autorino. 2011. Laparoendoscopic single site (LESS) adrenalectomy: Technique and outcomes. World Journal of Urology . [CrossRef]

24. Daniel R. Cox, Wenjing Zeng, Margaret M. Frisella, L. Michael Brunt. 2011. Analysis of standard multiport versus singlesite access for laparoscopic skills training. Surgical Endoscopy 25:4, 1238-1244. [CrossRef]

25. Robert J. Stein, Andre K. Berger, Ricardo Brandina, Neil S. Patel, David Canes, Brian H. Irwin, Monish Aron, Riccardo Autorino, Gaurang Shah, Mihir M. Desai. 2011. Laparoendoscopic single-site pyeloplasty: a comparison with the standard laparoscopic technique. BJU International 107:5, 811-815. [CrossRef]

26. Jae Duck Choi, Hong Seok Kim, Sung Ho Ju, Seo Yeon Lee, Deok Hyun Han, Byong Chang Jeong. 2011. Initial experience with LESS and hybrid LESS in patients with benign urologic disease. Minimally Invasive Therapy \& Allied Technologies 1-8. [CrossRef]

27. Nina Casanova , J. Stuart Wolf , Jr. . 2011. The Alternative to Laparoendoscopic Single-Site Surgery: Small Strategic Laparoscopic Incision Placement (SLIP) Nephrectomy Improves Cosmesis Without Technical Restrictions. Journal of Endourology 25:2, 265-270. [Abstract] [Full Text HTML] [Full Text PDF] [Full Text PDF with Links]

28. Matthew T. Gettman, Wesley M. White, Monish Aron, Riccardo Autorino, Tim Averch, Geoffrey Box, Jeffrey A. Cadeddu, David Canes, Edward Cherullo, Mihir M. Desai, Igor Frank, Indebir S. Gill, Mantu Gupta, Georges-Pascal Haber, Mitchell R. Humphreys, Brian H. Irwin, Jihad H. Kaouk, Louis R. Kavoussi, Jaime Landman, Evangelos N. Liatsikos, Estevao Lima, Lee E. Ponsky, Abhay Rane, Maria Ribal, Robert Rabenhalt, Pradeep Rao, Lee Richstone, Mark D. Sawyer, Rene Sotelo, JensUwe Stolzenburg, Chad R. Tracy, Robert J. Stein. 2011. Where Do We Really Stand With LESS and NOTES?. European Urology 59:2, 231-234. [CrossRef]

29. Jens-Uwe Stolzenburg, Minh Do , Panagiotis Kallidonis, Anja Dietel, Min-A Oh, Holger Till, Evangelos N. Liatsikos . 2011. Laparoendoscopic Single-Site Bladder Diverticulectomy: Technique and Initial Experience. Journal of Endourology 25:1, 85-90. [Abstract] [Full Text HTML] [Full Text PDF] [Full Text PDF with Links]

30. Kyung Hwa Choi, Won Sik Ham, Koon Ho Rha, Jae Won Lee, Hwang Gyun Jeon, Francis Raymond P. Arkoncel, Seung Choul Yang, Woong Kyu Han. 2011. Laparoendoscopic Single-Site Surgeries: A Single-Center Experience of 171 Consecutive Cases. Korean Journal of Urology 52:1, 31. [CrossRef]

31. Riccardo Autorino, Jeffrey A. Cadeddu, Mihir M. Desai, Matthew Gettman, Inderbir S. Gill, Louis R. Kavoussi, Estevão Lima, Francesco Montorsi, Lee Richstone, Jens U. Stolzenburg, Jihad H. Kaouk. 2011. Laparoendoscopic Single-site and Natural Orifice Transluminal Endoscopic Surgery in Urology: A Critical Analysis of the Literature. European Urology 59:1, 26-45. [CrossRef]

32. Masaru Ishida, Akira Miyajima, Toshikazu Takeda, Masanori Hasegawa, Eiji Kikuchi, Mototsugu Oya. 2010. Technical difficulties of transumbilical laparoendoscopic single-site adrenalectomy: comparison with conventional laparoscopic adrenalectomy. World Journal of Urology . [CrossRef]

33. Salvatore Micali, Giovannalberto Pini, Dogu Teber, Maria Chiara Sighinolfi, Stefano Stefani, Giampaolo Bianchi, Jens Rassweiler. 2010. New trends in minimally invasive urological surgery. What is beyond the robot?. World Journal of Urology . [CrossRef]

34. Rakesh Khanna, Riccardo Autorino, Michael A. White, Humberto Laydner, Sylvain Forest, Fatih Altunrende, Bo Yang, Georges-Pascal Haber, Jihad H. Kaouk, Robert J. Stein. 2010. Laparoendoscopic single-site surgery: current clinical experience. BJU International 106:6b, 897-902. [CrossRef]

35. Chang Wook Jeong, Yong Hyun Park, Chan Soo Shin, Hyeon Hoe Kim . 2010. Synchronous Bilateral Laparoendoscopic Single-Site Adrenalectomy. Journal of Endourology 24:8, 1301-1305. [Abstract] [Full Text HTML] [Full Text PDF] [Full Text PDF with Links] 
36. Arthur Rawlings, Steven E. Hodgett, Brent D. Matthews, Steven M. Strasberg, Mary Quasebarth, L. Michael Brunt. 2010. Single-Incision Laparoscopic Cholecystectomy: Initial Experience with Critical View of Safety Dissection and Routine Intraoperative Cholangiography. Journal of the American College of Surgeons 211:1, 1-7. [CrossRef]

37. Carlos Moreno Sanz, José F. Noguera Aguilar, María Luz Herrero Bogajo, Antonio Morandeira Rivas, César García Llorente, Gloria Tadeo Ruíz, Ángel Cuadrado García, Joaquín S. Picazo Yeste. 2010. Cirugía laparoscópica a través de incisión única. Cirugía Española 88:1, 12-17. [CrossRef]

38. Riccardo Autorino, Robert J Stein, Estevão Lima, Rocco Damiano, Rakesh Khanna, Georges-Pascal Haber, Michael A White, Jihad H Kaouk. 2010. Current status and future perspectives in laparoendoscopic single-site and natural orifice transluminal endoscopic urological surgery. International Journal of Urology 17:5, 410-431. [CrossRef]

39. Seok Young Lee, Yong Tae Kim, Hae Young Park, Tchun Yong Lee, Sung Yul Park. 2010. Initial Experience with Laparoendoscopic Single-Site Surgery by Use of a Homemade Transumbilical Port in Urology. Korean Journal of Urology 51:9, 613. [CrossRef]

40. Carlos Moreno Sanz, José F. Noguera Aguilar, María Luz Herrero Bogajo, Antonio Morandeira Rivas, César García Llorente, Gloria Tadeo Ruiz, Ángel Cuadrado García, Joaquín S. Picazo Yeste. 2010. Single incision laparoscopic surgery. Cirugía Española (English Edition) 88:1, 12-17. [CrossRef] 